\title{
IgG4-Related Disease Presenting as a Soft Tissue Tumor Affecting Skeletal Muscle: A Case Report
}

\author{
David Sáez Martínez ${ }^{1}$, Felipe López Oliva ${ }^{1}$, María Jesús Fernández Aceñero ${ }^{2}$, \\ Elena Fontoira Moyer ${ }^{3}$, Juan Luis Arranz Cozar ${ }^{4}$ \\ ${ }^{1}$ Ortrhopedic Surgery Department, Fundación Jiménez Díaz, Madrid, Spain; ²Pathology Department, Fundación Jiménez Díaz, Mad- \\ rid, Spain; ${ }^{3}$ Radiology Department, Fundación Jiménez Díaz, Madrid, Spain; ${ }^{4}$ Oncology Department, Fundación Jiménez Díaz, Mad- \\ rid, Spain. \\ Email: DSaezM@fjd.es
}

Received October $30^{\text {th }}, 2013$; revised November $28^{\text {th }}$, 2013; accepted December $15^{\text {th }}, 2013$

Copyright ( 2013 David Sáez Martínez et al. This is an open access article distributed under the Creative Commons Attribution License, which permits unrestricted use, distribution, and reproduction in any medium, provided the original work is properly cited. In accordance of the Creative Commons Attribution License all Copyrights (C) 2013 are reserved for SCIRP and the owner of the intellectual property David Sáez Martínez et al. All Copyright (C) 2013 are guarded by law and by SCIRP as a guardian.

\begin{abstract}
Background: IgG4-related disease is a systemic lymphoproliferative syndrome that shows IgG4-producing plasma cell expansion in affected organs with fibrotic or sclerotic changes. The lacrimal glands, salivary glands and pancreas are typically affected. We report a case of IgG4-related disease presenting a soft tissue tumor affecting skeletal muscle. Case Report: A 32-year-old man presented a soft tissue mass in his left arm. Magnetic resonance imaging revealed a spindle like, peripheral mass, in the lateral head of the triceps of his left arm. Tru-Cut Biopsy provided the diagnosis of IgG4-related disease affecting skeletal muscle. Glucocorticoid treatment was effective. Conclusion: To our knowledge, this is the first reported case of IgG4-related disease affecting skeletal muscle and presenting a soft tissue mass.
\end{abstract}

Keywords: IgG4-Related Disease; Soft Tissue Mass; Skeletal Muscle

\section{Introduction}

Immunoglobulin G4-related disease (IgG4-RD) is an increasingly recognized lymphoproliferative syndrome of unknown etiology. Patients show tumor-like swelling of involved organs, lymphoplasmacytic and IgG4 producing plasma cells infiltrating and affected organs with fibrotic or sclerotic changes. Elevated serum concentrations of IgG4 are found in $60 \%$ of patients with IgG4-RD.

The lacrimal glands, salivary glands and pancreas are the major affected organs.

Another feature of IgG4-RD is good glucocorticoid responsiveness.

We report the first case to our knowledge of IgG4-RD presenting a soft tissue tumor affecting skeletal muscle in the arm.

\section{Case Report}

A 32-year-old man was referred to our institution presenting a soft tissue mass in his left arm.

He had a medical history of asthma, left hypertrophic pachymeningitis and an orbital pseudotumor waiting for surgery.

Physical examination found a hard, nontender and mobile mass, with well defined borders, in the lateral aspect of his left arm, measuring $3 \times 3 \mathrm{~cm}$ in size. It showed mild growing during the last two years. Tinel Test was negative. He also presented a right exophthalmos.

Complete blood count and serum chemistry, including IgG levels (787 mg/dl), were all within their normal limits (Table 1).

The MRI described a spindle like, peripheral mass, in the lateral head of the triceps, with well demarcated borders, T1 and T2 hyperintense and hypercaptant with contrast. It had a central hypointense region in all sequences that could correspond to fibrosis. It measured $2 \mathrm{~cm} \times 17$ $\mathrm{mm} \times 2.5 \mathrm{~cm}$ (Figure 1).

An ultrasound guided Tru-Cut Biopsy was performed, referring 4 cylinders of material to Soft Tissue Pathology Department. The biopsy showed a fibro inflammatory condition, with abundant plasma cells, dissecting and 
Table 1. Regular laboratory results.

\begin{tabular}{|c|c|c|}
\hline Parameter & Value & Units \\
\hline Erythrocytes (RBC) & 4.21 & ${ }^{*} 10^{6} / \mathrm{mm}^{3}$ \\
\hline Hematocrit & 43.2 & $\%$ \\
\hline White blood cell count & 9.60 & $* 10^{3} / \mathrm{mm}^{3}$ \\
\hline Segmented neutrophils & 78.7 & $\%$ \\
\hline Lymphocytes & 9.9 & $\%$ \\
\hline Monocytes & 9.5 & $\%$ \\
\hline Eosinophils & 1.2 & $\%$ \\
\hline Basophils & 0.7 & $\%$ \\
\hline INR & 1 & \\
\hline Platelet count & 163 & ${ }^{*} 10^{3} / \mathrm{mm}^{3}$ \\
\hline Fibrinogen & 416 & $\mathrm{mg} / \mathrm{dl}$ \\
\hline Creatinine, serum & 1.04 & $\mathrm{mg} / \mathrm{dl}$ \\
\hline Gamma glutamyl transferase (GGT) & 17 & $\mathrm{U} / \mathrm{l}$ \\
\hline Glucose & 99 & $\mathrm{mg} / \mathrm{dl}$ \\
\hline Lactate dehydrogenase serum (LDH) & 4 & $\mathrm{mEq} / \mathrm{l}$ \\
\hline Potassium & 140 & $\mathrm{mEq} / \mathrm{l}$ \\
\hline Sodium serum & 74 & $\mathrm{mg} / \mathrm{dl}$ \\
\hline Triglyceride & 5.3 & $\mathrm{mg} / \mathrm{dl}$ \\
\hline \multicolumn{3}{|l|}{ Uric acid } \\
\hline Erythrocyte sedimenttion rate & 2 & $\mathrm{~mm} / \mathrm{h}$ \\
\hline IgG serum & 787 & $\mathrm{mg} / \mathrm{dl}$ \\
\hline IgA serum & 92.8 & $\mathrm{mg} / \mathrm{dl}$ \\
\hline IgM serum & 51 & $\mathrm{mg} / \mathrm{dl}$ \\
\hline
\end{tabular}
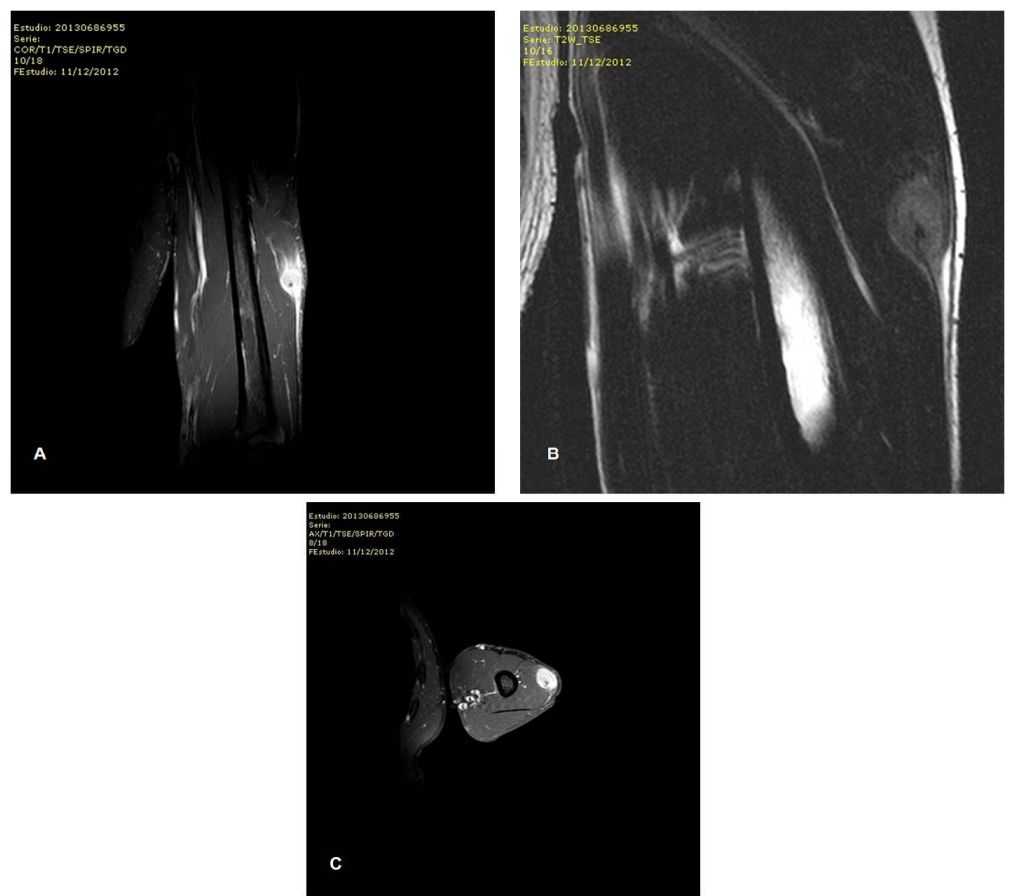

Figure 1. (A)-(C) Magnetic resonance images showed a well defined peripheral mass in the lateral head of the triceps hyper intense and hypercaptant with contrast. 
infiltrating the skeletal muscle, causing degeneration and atrophy of muscular cells. Immunohistochemical analysis using CD 38 marker (plasma cell marker) and IgG4 stain revealed an increased IgG4 (+) plasma cell count (Figure 2).

Surgical treatment of his orbital pseudotumor was done. The biopsy of the orbital lesion showed an inflammatory pseudotumor. The soft tissue mass in his arm had a very good responsiveness to glucocorticoid treatment initiated after the neurosurgical procedure, reducing its size so no surgical treatment of the arm mass was indicated.
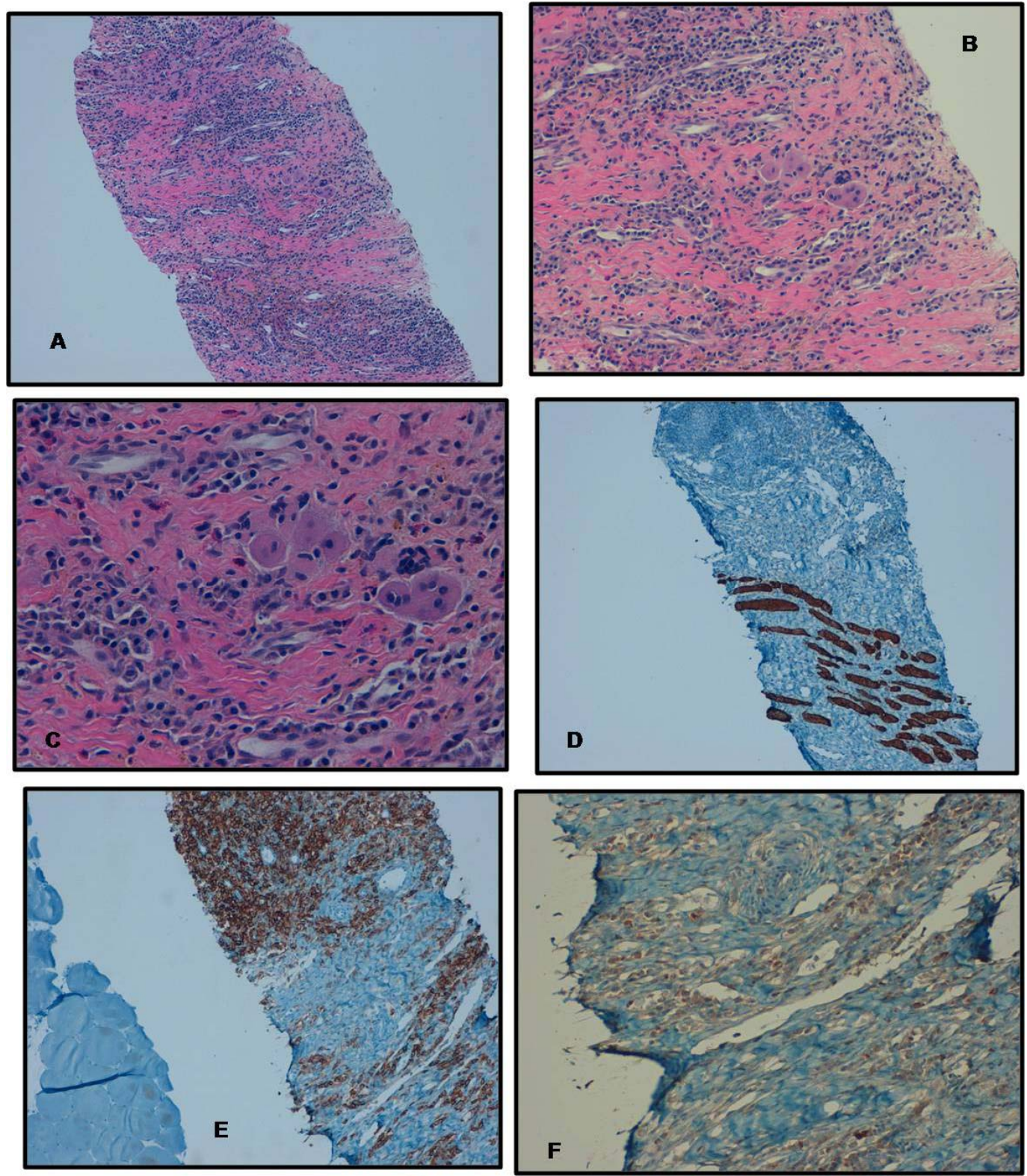

Figure 2. Histopathological Findings. (A)-(C) Sections of the lesion show a fibroinflammatory condition affecting the skeletal muscle (A, H \& E, $\times 100$. B, H \& E, $\times 200$. C, H \& E, $\times 400)$. (D) Desmin stain $\times 100$ positive for skeletal muscle. (E) CD 38 marker positive indicating plasma cell infiltration. (F) IgG4 stain positive revealed an increased IgG4 plasma cell count. 
must be biopsied [1].

IgG4-RD is a novel lymphoproliferative syndrome of unknown etiology including a collection of disorders that share clinical and pathological characteristics. Several of the manifestations can occur in the same patient and comprise: Type 1 autoinmune pancreatitis and IgG4-related sclerosing cholangitis, inflammatory orbital pseudotumor, retroperitoneal fibrosis, thyroiditis, and other sclerosing or IgG4-related disorders as dacryoadenitis, sialadenitis, aortitis and periaortitis, interstitial pneumonitis, tubulointerstitial nephritis, hypertrophic pachymeningitis [2].

The principal symptoms and signs of IgG4-RD are a slow growing mass or diffuse enlargement of an organ. To our knowledge this is the first reported case of localized IgG4-related disease affecting skeletal muscle and presenting as a soft tissue tumor. IgG4-RD can also present with clinical findings related to affected organs with fibrotic or sclerotic changes [2].

Pathologically the disease is characterized by IgG4 positive plasma cells and lymphocytes tissue infiltration which may be accompanied by sclerosis. Elevated serum levels of IgG4 may be present, being an important aid in diagnosis, although they are not diagnostic [3].

The diagnosis of IgG4-RD is made with biopsy findings demonstrating the characteristic histopathology. CoreNeedle Biopsy or Tru-Cut Biopsy is most often indicated for superficial or accessible deep extremity soft tissue tumors that are of sufficient size to needle placement $(>3$ $\mathrm{cm})$ [1]. In our case this was the technique of biopsy indicated. A good therapeutic response to glucocorticoids is also characteristic of IgG4-RD, by symptomatic and organ function improvement or reductions in the size of masses, as it happened in our case [4,5].

Glucocorticoid therapy has been suggested as the initial treatment of IgG4-RD. Azathioprine, mycophenolate mofetil and rituximab have been used to treat resistant patients [5,6].

The natural history and prognosis of IgG4-related dis- ease are not well described. Despite that good responsiveness to glucocorticoid treatment, relapses are common and organ dysfunction may arise from inflammatory and fibrotic changes. The possibility of increased risk of malignancy is not clear $[5,6]$.

\section{Conclusion}

Despite its extreme rarity, IgG4-related disease may be presented as a soft tissue tumor affecting skeletal muscle. Biopsy may be the only diagnostic procedure. A good therapeutic response to glucocorticoids should be expected.

\section{REFERENCES}

[1] T. A. Damron, “Oncology and Basic Science,” Lippincott Williams \& Wilkins, Philadelphia, 2008

[2] J. H. Stone, Y. Zen and V. Deshpande, "Mechanisms of disease: IgG4-related disease,” The New England Journal of Medicine, Vol. 366, No. 6, 2012, pp. 539-551. http://dx.doi.org/10.1056/NEJMra1104650

[3] H. Umehara, K. Okazaki, Y. Masaki, et al., "Comprehensive Diagnostic Criteria for IgG4-Related Disease (IgG4RD), 2011,” Modern Rheumatology, Vol. 22, No. 1, 2012, pp. 21-30. http://dx.doi.org/10.1007/s10165-011-0571-z

[4] M. Yasufumi, K. Nozomu and U. Hisanori, "IgG4-Related Disease: A Novel Lymphoproliferative Disorder Discovered and Established in Japan in the $21^{\text {st }}$ Century," Journal of Clinical and Experimental Hematopathology, Vol. 51, No. 1, 2011, pp. 13-20. http://dx.doi.org/10.3960/jslrt.51.13

[5] H. M. Moutsopoulos, G. E. Fragoulis and J. H. Stone, “Overview of IgG4-Related Disease,” 2013. http://www.uptodate.com/contents/overview-of-igg4-relat ed-disease

[6] M. N. Carruthers, J. H. Stone and A. Khosroshahi, "The Latest on IgG4-RD: A Rapidly Emerging Disease,” Current Opinion in Rheumatology, Vol. 24, No. 1, 2012, pp. 60-69. http://dx.doi.org/10.1097/BOR.0b013e32834ddb4a 